\title{
Effective treatment of cadmium-cyanide complex by a reagent with combined function of oxidation and coagulation
}

\author{
Chengzhi Hu, Liyan You, Huijuan Liu*, Jiuhui Qu \\ Key Laboratory of Drinking Water Science and Technology, Research Center for Eco-Environmental Sciences, Chinese Academy of Sciences, Beijing 100085, China
}

\section{H I G H L I G H T S}

- PACC is an efficient dual function reagent for $\left[\mathrm{Cd}(\mathrm{CN})_{4}\right]^{2-}$ treatment. - $\mathrm{CN}^{-}$oxidation and $\mathrm{Cd}^{2+}$ coagulation can be simultaneously achieved.

- Two stages need be carried out for complete removal of $\left[\mathrm{Cd}(\mathrm{CN})_{4}\right]^{2-}$.

- The optimum working conditions of PACC are presented.

\section{A R T I C L E I N F O}

\section{Article history:}

Received 22 July 2014

Received in revised form 19 September

2014

Accepted 23 September 2014

Available online 2 October 2014

\section{Keywords:}

Cyanide

Heavy metal

Oxidation

Coagulation

Water treatment
G R A P H I C A L A B S T R A C T

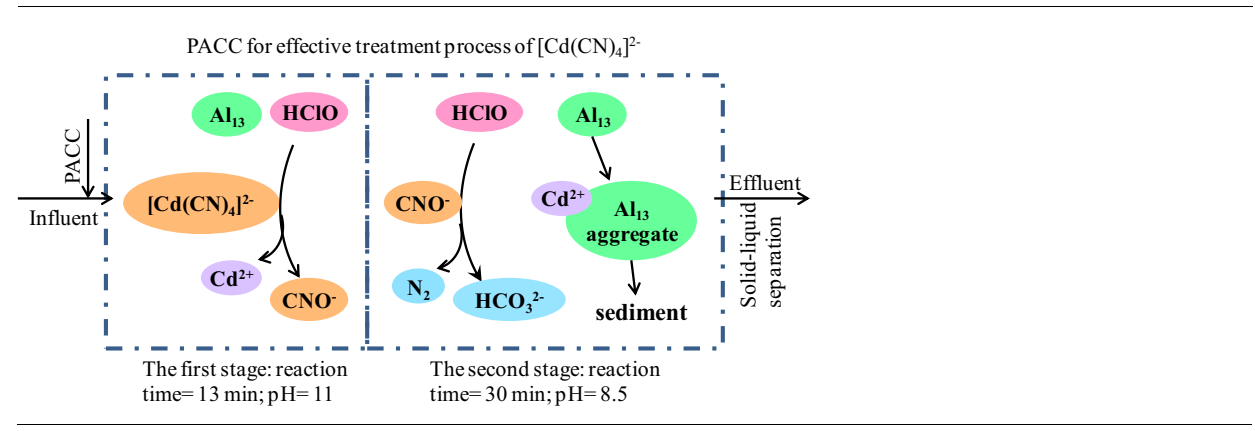

\begin{abstract}
A B S T R A C T
The treatment of heavy metal-cyanide complex in industrial wastewater generally involves various processing units, such as chemical oxidation, hydrolysis precipitation and coagulation. A novel dual function reagent (PACC), which contains high content of active chlorine and $\mathrm{Al}_{13}$ polymer, shows a promising potential to shorten the process and heighten the treatment efficiency for cadmium-cyanide complex $\left(\left[\mathrm{Cd}(\mathrm{CN})_{4}\right]^{2-}\right)$. The results indicated that PACC is able to simultaneously achieve the complete oxidation of cyanide $\left(\mathrm{CN}^{-}\right)$by active chlorine and the subsequent coagulation of cadmium ion $\left(\mathrm{Cd}^{2+}\right)$ by $\mathrm{Al}_{13}$ polymer. Two stages were carried out for complete $\mathrm{CN}^{-}$oxidation and effective $\mathrm{Cd}^{2+}$ coagulation. The first stage involves the conversion of $\mathrm{CN}^{-}$to cyanate $\left(\mathrm{CNO}^{-}\right)$, and the second stage involves the conversion of $\mathrm{CNO}^{-}$to nitrogen and the coagulation of the liberated $\mathrm{Cd}^{2+}$. The optimum $\mathrm{pH}$ values for the first stage and the second stage are $\mathrm{pH} 11$ and $\mathrm{pH} 8.5$, respectively. The two stages for effective treatment of $\left[\mathrm{Cd}(\mathrm{CN})_{4}\right]^{2-}$ at the optimal pH condition totally need about $43 \mathrm{~min}$ at active chlorine dosage $130 \%$ of the theoretical requirement for $\mathrm{CN}^{-}$decomposition. Under the optimal conditions for $\left[\mathrm{Cd}(\mathrm{CN})_{4}\right]^{2-}$ treatment, the stoichiometric weight ratio of $\mathrm{Cl}_{2} / \mathrm{Al}$ in PACC is 2 . This study presents a novel reagent and method to remove heavy metal-cyanide complexes from wastewater.
\end{abstract}

(c) 2014 Elsevier B.V. All rights reserved.

\section{Introduction}

Cyanide and Cadmium (Cd) are very toxic to many life forms, and appear on international priority pollution lists. Cyanide ion $\left(\mathrm{CN}^{-}\right)$has a great tendency to act as a ligand, and associates with almost any metal ions to form complex [1]. Cadmium-cyanide

\footnotetext{
* Corresponding author. Tel.: +86 10 62849128; fax: +86 1062849160 .

E-mail address: hjliu@rcees.ac.cn (H. Liu).
}

complex $\left(\left[\mathrm{Cd}(\mathrm{CN})_{4}\right]^{2-}\right)$ is widely found in electroplating and mining effluents. Since neutral and acidic conditions favor the conversion of cyanide to hydrogen cyanide that is exceedingly poisonous and readily evolves from water in gaseous phase [2], the treatment of cyanide must be conducted at alkaline condition. The bound $\mathrm{Cd}^{2+}$ by $\mathrm{CN}^{-}$is quiet stable at alkaline condition [2]. Thus, it is difficult to be removed by conventional hydrolysis precipitation. The addition of oxidizing chemicals is the most popular method to destroy and remove cyanides [2], and then $\mathrm{Cd}^{2+}$ is liberated and 
available to be removed by hydrolysis precipitation and coagulation $[3,4]$. Fe(VI) has been reported to be effective for treating heavy metal-cyanide complex due to cyanide oxidation by $\mathrm{Fe}(\mathrm{VI})$ and subsequent removal of heavy metal by Fe(III) coagulation [5,6].

The alkaline chlorination method is the most widely applied for destruction of heavy metal cyanide complex and removal of cyanide from wastewater [2,7]. Coagulation using $\mathrm{Al}$ and Fe based salts followed by sedimentation and filtration is also employed to remove heavy metal from wastewater $[4,8]$. With high content of $\mathrm{Al}_{13}$ polymer $\left(\mathrm{AlO}_{4} \mathrm{Al}_{12}(\mathrm{OH})_{24}\left(\mathrm{H}_{2} \mathrm{O}\right)_{12}^{7+}\right)$ and active chlorine, a novel water treatment reagent (PACC) that can be synthesized by an electrochemical method $[9,10]$ presents the dual function of coagulation and oxidation $[9,11]$. It is believed that $\mathrm{Al}_{13}$ polymer, with high positive charge and strong binding ability, is the most active species in $\mathrm{Al}$ based coagulants responsible for coagulation $[12,13]$. Active chlorine is the most widely used as a disinfectant and pre-oxidant in water treatment process. Therefore, PACC has the potential to simultaneously remove $\mathrm{CN}^{-}$and $\mathrm{Cd}^{2+}$, which may offer significant advantages in practice since the treatment process of $\left[\mathrm{Cd}(\mathrm{CN})_{4}\right]^{2-}$ can be shortened. Water treatment buildings are expected to be more compact and less management is required when using PACC, in comparison with the conventional two-unit system using alkaline chlorination and coagulation separately.

The present study was to evaluate the performance of PACC on $\left[\mathrm{Cd}(\mathrm{CN})_{4}\right]^{2-}$ removal through $\mathrm{CN}^{-}$oxidation by active chlorine and subsequent removal of $\mathrm{Cd}^{2+}$ by $\mathrm{Al}_{13}$ species coagulation. The kinetics and stoichiometry of the complete oxidation of $\mathrm{CN}^{-}$by active chlorine in PACC were investigated. The effect of $\mathrm{pH}$, dosage and reaction time on the $\mathrm{CN}^{-}$oxidation and $\mathrm{Cd}^{2+}$ coagulation were studied to illuminate the optimum work conditions for $\left[\mathrm{Cd}(\mathrm{CN})_{4}\right]^{2-}$ removal by PACC.

\section{Materials and methods}

\subsection{Water samples}

All reagents and chemicals used were of analytical grades. The stock solution of $\mathrm{NaCN}$ was prepared in $\mathrm{NaOH}$ solution, then it mixed with $\mathrm{CdCl}_{2}$ solution for $6 \mathrm{~h}$ to attain $\left[\mathrm{Cd}(\mathrm{CN})_{4}\right]^{2-}$ stock solution. Water sample was synthesized by spiking a certain volume of stock solution into deionized water containing $5 \times 10^{-4} \mathrm{~mol} / \mathrm{L}$ of $\mathrm{NaHCO}_{3}$ and $\mathrm{NaNO}_{3}$.

\subsection{The characteristics of PACC}

PACC samples were prepared according to the method was described in our previous papers $[9,10]$. The properties of PACC used are summarized in Table 1. PACC1 was a general reagent for the most experiments, while PACC2 was specially prepared to evaluate the performance of $[\mathrm{Cd}(\mathrm{CN}) 4]^{2-}$ removal. The $\mathrm{Al}_{13}$ species was the predominant $\mathrm{Al}$ speciation for PACC. Total Al concentrations $\left(\mathrm{Al}_{\mathrm{T}}\right)$ were determined using ICP-OES (PerkinElmer, Optima 2000, UK). Basicity values ( $\mathrm{B}, \mathrm{OH} / \mathrm{Al}$ molar ratio) were determined by standard titrimetric methods (Standard method of the chemical industry of China). Active chlorine was determined by spectrophotometry using $\mathrm{N}, \mathrm{N}$-diethyl-1,4-phenylenediamine. The weight ratio of $\mathrm{Cl}_{2} / \mathrm{Al}$ in PACC can be adjusted by regulating electrolyte

Table 1

Characteristics of PACC.

\begin{tabular}{llllllll}
\hline Coagulant & $\mathrm{B}$ & $\begin{array}{l}\mathrm{Al}_{\mathrm{T}} \\
(\mathrm{g} / \mathrm{L})\end{array}$ & $\begin{array}{l}\text { Active chloride } \\
\left(\mathrm{g} \mathrm{Cl}_{2} / \mathrm{L}\right)\end{array}$ & $\begin{array}{l}\text { Weight ratio } \\
\left(\mathrm{Cl}_{2} / \mathrm{Al}\right)\end{array}$ & $\mathrm{Al}_{\mathrm{m}}$ & $\mathrm{Al}_{13}(\%)$ & $\mathrm{Al}_{\mathrm{u}}$ \\
\hline PACC1 & 2.5 & 1.6 & 6.0 & 3.8 & 8.50 & 79.02 & 12.48 \\
PACC2 & 2.4 & 2.7 & 5.4 & 2.0 & 7.43 & 81.67 & 10.90 \\
\hline
\end{tabular}

$\mathrm{Al}_{\mathrm{T}}, \mathrm{B}$ value, and temperature during preparation. We used ${ }^{27} \mathrm{Al}$ nuclear magnetic resonance (NMR) spectroscopy to characterize the Al species with ${ }^{27} \mathrm{Al}$ NMR spectra obtained on a Varian UNITY INOVA $(500 \mathrm{MHz})$ spectrometer. Each of $\mathrm{Al}_{\mathrm{m}}$ (i.e. monomer + dimer), $\mathrm{Al}_{13}$, and $\mathrm{Al}_{\mathrm{u}}$ [i.e. larger polymer species and/or solid phase $\left.\mathrm{Al}(\mathrm{OH})_{3}\right)$ ] can be quantitatively analyzed according to the intensities of ${ }^{27} \mathrm{Al}$ signals. Details of the quantitative analysis of the $\mathrm{Al}$ species can be found in literature $[9,10]$.

\subsection{Performance of $\left[\mathrm{Cd}(\mathrm{CN})_{4}\right]^{2-}$ removal}

The experiments of $\mathrm{CN}^{-}$and $\mathrm{Cd}^{2+}$ removal by PACC or $\mathrm{NaClO}$ were conducted using jar test, which was performed using a sixpaddle stirrer. The concentration of $\mathrm{CN}^{-}$assessed in this study was $0.18-2.8 \mathrm{mmol} / \mathrm{L}$, which simulated the practical water quality of industry effluent [2]. The concentration of $\mathrm{Cd}^{2+}$ in this study was determined according to the concentration of $\mathrm{CN}^{-}$, since $\mathrm{CN}^{-}$is the ligand of $\mathrm{Cd}^{2+}$. The procedure of jar test consisted of a rapid mix of $250 \mathrm{rpm}$, slow mix of $40 \mathrm{rpm}$, and a 30 min settling period. After settling for $30 \mathrm{~min}$, supernatants were sampled and filtered by $0.45 \mu \mathrm{m}$ pore size membrane filter. PACC or $\mathrm{NaClO}$ were added into water samples at the beginning of rapid mix period. The filtrates were tested for cyanate $\left(\mathrm{CNO}^{-)}\right.$concentration using ion chromatograph (Dionex, ICS-2000, USA) and $\mathrm{Cd}^{2+}$ concentration using ICP-OES (PerkinElmer, Optima 2000, UK). Before PACC dosing a predetermined amount of $0.2 \mathrm{~mol} / \mathrm{L} \mathrm{NaOH}$ or $0.05 \mathrm{~mol} / \mathrm{L} \mathrm{HCl}$ solution was added into water samples to approximatively get an expected $\mathrm{pH}$ value. After dosing, water $\mathrm{pH}$ was accurately regulated to the expected value during rapid mix period by adding $\mathrm{HCl}$ or $\mathrm{NaOH}$ solution, after which water $\mathrm{pH}$ was constant during subsequent oxidation and coagulation process.

\subsection{Stoichiometry}

The stoichiometry of $\mathrm{CN}^{-}$and $\mathrm{CNO}^{-}$oxidation by PACC were examined by analysis of the formed and residual $\mathrm{CNO}^{-}$, respectively. The reactions were conducted using a magnetic stirrer. The reaction time of $\mathrm{CN}^{-}$and $\mathrm{CNO}^{-}$oxidation by PACC were $30 \mathrm{~min}$ and $1 \mathrm{~h}$, respectively. A certain amount of water was sampled at the end of reactions for $\mathrm{CNO}^{-}$analysis. Before reaction, water $\mathrm{pH}$ values were regulated at either 11 or 8.5 by adding $0.2 \mathrm{~mol} / \mathrm{L}$ of $\mathrm{NaOH}$ or $0.05 \mathrm{~mol} / \mathrm{L}$ of $\mathrm{HCl}$ solution. Water $\mathrm{pH}$ was not adjusted during the reaction process. The PACC dosages gradually increased, while the $\mathrm{CN}^{-}$and $\mathrm{CNO}^{-}$concentration was fixed at $0.34 \mathrm{mmol} / \mathrm{L}$ and $0.48 \mathrm{mmol} / \mathrm{L}$, respectively.

\subsection{Stopped-flow kinetic}

Apparent rate constants at various $\mathrm{pH}$ values for the reaction of $\mathrm{CN}^{-}$and $\mathrm{CNO}^{-}$oxidation by PACC were determined using an Applied Photophysics SX20 stopped-flow spectrophotometer. Kinetic studies were carried out under pseudo-first-order conditions at $25^{\circ} \mathrm{C}$. The concentrations of $\mathrm{CN}^{-}$or $\mathrm{CNO}^{-}$were kept in excess of active chlorine by at least 1 order of magnitude. Active chlorine absorbance at $292 \mathrm{~nm}$ was followed as a function of time to determine rate constants. In all experiments, PACC and $\left[\mathrm{Cd}(\mathrm{CN})_{4}\right]^{2-}$ solutions were buffered by $0.1 \mathrm{M}$ phosphate to attain the desired $\mathrm{pH}$.

\section{Results and discussions}

\subsection{Stoichiometric study}

A complete $\mathrm{CN}^{-}$treatment by alkaline-chlorination-oxidation method should be carried out into two stages [14,15]. The first 
stage is the conversion of $\mathrm{CN}^{-}$to $\mathrm{CNO}^{-}$at strong alkaline environment and the second stage involves the transformation of $\mathrm{CNO}^{-}$to nitrogen and carbonates at mild alkaline condition. The stoichiometries of $\mathrm{CN}^{-}$and $\mathrm{CNO}^{-}$oxidation by PACC were determined at $\mathrm{pH}$ 11 and $\mathrm{pH} 8.5$, respectively. When the initial active chlorine in PACC increased from 0 to $0.34 \mathrm{mmol} / \mathrm{L}, \mathrm{CNO}^{-}$linearly increased with a slop of 0.96 (Fig. 1). When the initial active chlorine concentration was greater than $0.34 \mathrm{mmol} / \mathrm{L}$, the formed $\mathrm{CNO}^{-}$was constant at $0.34 \mathrm{mmol} / \mathrm{L}$, which was equal to the initial concentration of $\mathrm{CN}^{-}$. These results indicated that the conversion of $\mathrm{CN}^{-}$to $\mathrm{CNO}^{-}$by the oxidation of active chlorine followed a stoichiometric rate (SR) of $1.04 \mathrm{~mol} \mathrm{Cl}_{2} / \mathrm{mol} \mathrm{CN}^{-}$, which was very close to the theoretical SR [ $1 \mathrm{~mol} \mathrm{Cl}_{2} / \mathrm{mol} \mathrm{CN}^{-}$] according to the reaction of $\mathrm{CN}^{-}$with hypochlorite (Eq. (1)).

$\mathrm{CN}^{-}+\mathrm{ClO}^{-} \rightarrow \mathrm{CNO}^{-}+\mathrm{Cl}^{-}$

An increase of PACC dosage resulted in a decrease of residual $\mathrm{CNO}^{-}$that followed linear relationship (Fig. 2). The slope of the linear line presented stoichiometries for the reaction of $\mathrm{CNO}^{-}$with active chlorine as -0.64 , which is approximately consistent to the theoretical SR $\left[1.5 \mathrm{~mol} \mathrm{Cl}_{2} / \mathrm{mol} \mathrm{CNO}^{-}\right.$] according to the reaction of $\mathrm{CNO}^{-}$with hypochlorite (Eq. (2)).

$2 \mathrm{CNO}^{-}+3 \mathrm{ClO}^{-}+\mathrm{H}_{2} \mathrm{O} \rightarrow \mathrm{N}_{2}+3 \mathrm{Cl}^{-}+2 \mathrm{HCO}_{3}^{-}$

The final product of $\mathrm{CN}^{-}$is nitrogen and bicarbonate. Considering the two stage the proposed net reaction of $\left[\mathrm{Cd}(\mathrm{CN})_{4}\right]^{2-}$ with active chlorine in PACC is as Eq. (3), which indicates that the SR is $2.5 \mathrm{~mol} \mathrm{Cl}_{2} / \mathrm{mol} \mathrm{CN}^{-}$for complete oxidation of $\mathrm{CN}^{-}$by PACC.

$\left[\mathrm{Cd}(\mathrm{CN})_{4}\right]^{2-}+10 \mathrm{ClO}^{-}+2 \mathrm{H}_{2} \mathrm{O}=2 \mathrm{~N}_{2}+10 \mathrm{Cl}^{-}+4 \mathrm{HCO}_{3}^{-}+\mathrm{Cd}^{2+}$

\subsection{Determination of optimum working conditions}

\subsection{1. $\mathrm{pH}$}

The reaction rates of $\mathrm{CN}^{-}$and $\mathrm{CNO}^{-}$with active chlorine were determined using a stopped-flow spectrophotometer at different $\mathrm{pH}$ conditions. The rate expression for the reactions can be written as

$\frac{d\left[\mathrm{OCL}^{-}\right]}{d t}=-k_{\mathrm{obs}}\left[\mathrm{OCl}^{-}\right]$

where $k_{\mathrm{obs}}$ (determined by model fitting of experimental kinetic data) represents apparent first-order rate constant at a particular $\mathrm{pH}$ value. Fig. 3, which shows the magnitude of $k_{\mathrm{obs}}$ at various $\mathrm{pH}$ values, illustrates that the reaction rate of PACC with $\mathrm{CN}^{-}$and $\mathrm{CNO}^{-}$ decrease with the increase of $\mathrm{pH}$ value.

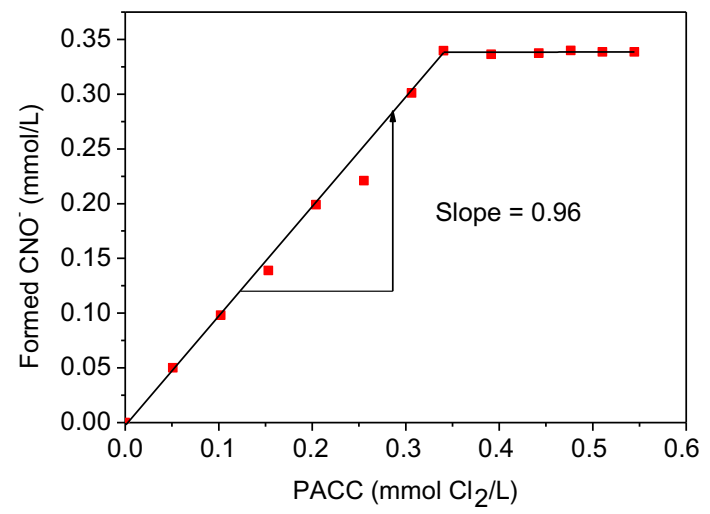

Fig. 1. Concentration plot for $\mathrm{CNO}^{-}$generated after the reaction of $0.085 \mathrm{mmol} / \mathrm{L}$ $\left[\mathrm{Cd}(\mathrm{CN})_{4}\right]^{2-}$ with various concentrations of PACC at initial $\mathrm{pH} 11$.

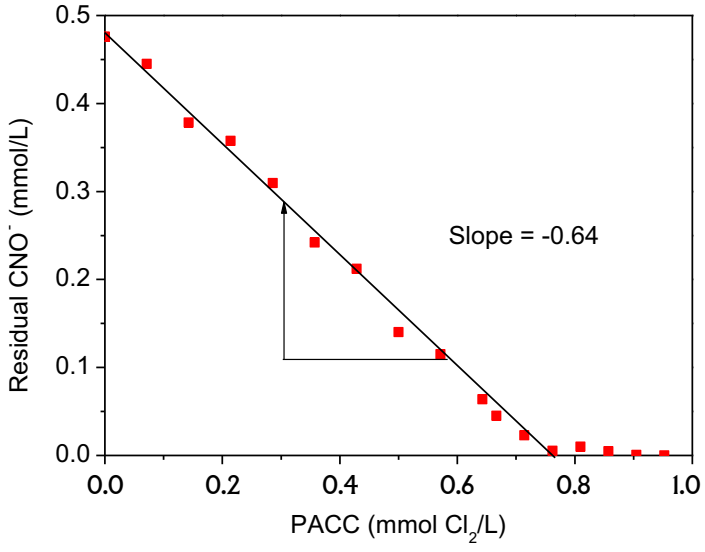

Fig. 2. Concentration plot for residual $\mathrm{CNO}^{-}$after the reaction of $0.48 \mathrm{mmol} / \mathrm{L} \mathrm{CNO}$ with various concentrations of PACC at initial $\mathrm{pH} 8.5$.
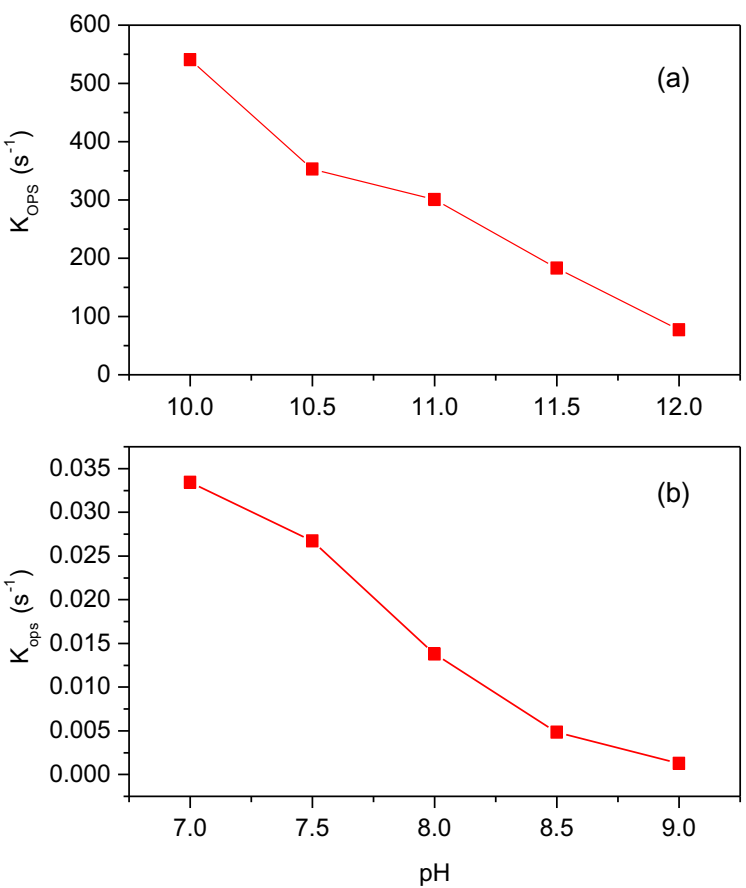

Fig. 3. Observed pseudo-first-order rate constant for $\mathrm{CN}^{-}$oxidation by PACC at different $\mathrm{pH}$ value (a, experiments conducted at $\left[\mathrm{CN}^{-}\right]=2.8 \mathrm{mmol} / \mathrm{L}$ and $\left[\mathrm{Cl}_{2}\right]=0.28 \mathrm{mmol} / \mathrm{L}$ ). Observed pseudo-first-order rate constant for $\mathrm{CNO}^{-}$oxidation by PACC at different $\mathrm{pH}$ value (b, experiments conducted at $\left[\mathrm{CNO}^{-}\right]=11.30 \mathrm{mmol} / \mathrm{L}$ and $\left[\mathrm{Cl}_{2}\right]=1.13 \mathrm{mmol} / \mathrm{L}$ )

In fact, the initial oxidation product of the reaction between $\mathrm{CN}^{-}$and hypochlorite is volatile cyanogens chloride (Eq. (5)) $[2,16]$.

$\mathrm{CN}^{-}+\mathrm{ClO}^{-}+\mathrm{H}_{2} \mathrm{O} \rightarrow \mathrm{CNCl}+2 \mathrm{OH}^{-}$

At alkaline $\mathrm{pH}$ environment, the formed $\mathrm{CNCl}$ formed undergoes rapid hydrolysis according to the following reaction (Eq. (6)).

$\mathrm{CNCl}+2 \mathrm{OH}^{-} \rightarrow \mathrm{CNO}^{-}+\mathrm{Cl}^{-}+\mathrm{H}_{2} \mathrm{O}$

The $k_{\text {obs }}$ values in Fig. 3 at different $\mathrm{pH}$ actually reflects the reaction rates of the conversion of $\mathrm{CN}^{-}$to $\mathrm{CNCl}$, and shows that PACC reacts very rapidly with $\mathrm{CN}^{-}$. For example, $k_{\text {obs }}$ is $300.42 \mathrm{~s}^{-1}$ at $\mathrm{pH} 11$, corresponding to a $t_{1 / 2}, \mathrm{CN}^{-}$of $2.31 \mathrm{~ms}$. A previous kinetics study [16] indicated that the half-lives of $\mathrm{CNCl}$ at $\mathrm{pH} 11$ and 9 were estimated to be 1.31 and $131 \mathrm{~min}$, respectively. Therefore, the decisive process for the reaction (Eq. (1)) rate is the hydrolysis of 
formed $\mathrm{CNCl}$ (Eq. (6)). The rate of $\mathrm{CNCl}$ hydrolysis is positively correlated with $\mathrm{pH}$ value. The time for $99.9 \%$ conversion takes about $13 \mathrm{~min}$ at $\mathrm{pH} 11$ [14,16]. Considering the facilitation of $\mathrm{CN}^{-}$ destruction and the cost of $\mathrm{pH}$ adjustment, $\mathrm{pH} 11$ was selected as the optimum $\mathrm{pH}$ condition for the first stage of $\left[\mathrm{Cd}(\mathrm{CN})_{4}\right]^{2-}$ treatment by PACC.

The effect of $\mathrm{pH}$ on $\mathrm{Cd}^{2+}$ removal by PACC coagulation has been examined under mildly alkaline (Fig. 4). The result indicates that high $\mathrm{pH}$ facilitates $\mathrm{Cd}^{2+}$ removal. It may be attributed to the lower solubility of $\mathrm{Cd}^{2+}$ at high $\mathrm{pH}$, which favors the generation of $\mathrm{Cd}(\mathrm{OH})_{2}(\mathrm{~s})$ that has a stronger affinity to the surface of hydrolyzed aluminum flocs. It has been demonstrated that $\mathrm{Al}_{13}$ species is very stable and is the predominant $\mathrm{Al}$ species during the coagulation process of $\mathrm{Al}_{13}$-rich polyaluminum chloride $(\mathrm{PACl})$ even at alkaline condition $[17,18]$. In addition, $\mathrm{Al}_{13}$-aggregate is the main composition in the hydroxide flocs of $\mathrm{Al}_{13}$-rich $\mathrm{PACl}$ [19]. Thereby $\mathrm{Al}_{13}$ polymer is the most active species responsible for the liberated $\mathrm{Cd}^{2+}$ removal by PACC coagulation. On the other hand, from Fig. 3, lowering $\mathrm{pH}$ in the alkaline region increased the reaction rate of active chlorine in PACC with $\mathrm{CNO}^{-}$, which is mainly due to the increase in the concentration of hypochlorous that is a more powerful oxidant comparing with hypochlorite [15]. Considering the facilitation of $\mathrm{CNO}^{-}$decomposition and $\mathrm{Cd}^{2+}$ removal together, $\mathrm{pH} 8.5$ was selected as the optimum $\mathrm{pH}$ condition for the second stage $\left[\mathrm{Cd}(\mathrm{CN})_{4}\right]^{2-}$ treatment by PACC, because it could not only meet the required $\mathrm{pH}$ environment for $\mathrm{CNO}^{-}$oxidation by active chlorine but also provide a suitable $\mathrm{pH}$ condition for $\mathrm{Cd}^{2+}$ coagulation by $\mathrm{Al}_{13}$ polymer.

\subsubsection{Reaction time and dosage}

The effect of reaction time on the complete $\mathrm{CN}^{-}$oxidation by PACC was investigated under one time dosage strategy at the start of the first stage. The conversion of $\mathrm{CN}^{-}$to $\mathrm{CNO}^{-}$with time is not presented here, since the reaction (Eq. (6)) of $\mathrm{CNCl}$ hydrolysis cannot be terminated. $\mathrm{CNO}^{-}$decomposition as a function of reaction time was monitored (Fig. 5). According to the last section and in prior studies, $13 \mathrm{~min}$ was used as the reaction time for the first stage, after which 2 min was used to regulate an appropriate $\mathrm{pH}$ for the second stage. The amount of PACC dosage was determined according to the SR (Eq. (3)), i.e. complete oxidation of $\mathrm{CN}^{-}$by active chlorine. Fig. 5 shows that the rate of $\mathrm{CNO}^{-}$decomposition increases with increasing active chlorine concentration, which was consistent with the previous results [14]. Complete $\mathrm{CNO}^{-}$ decomposition needed about 150 min when active chlorine dosage of theoretical requirement was used, while with an active chlorine dosage $130 \%$ of theoretical requirement a retention time of about 30 min was enough for complete oxidation. It was reported that overdosing of active chlorine could increase the conversion of

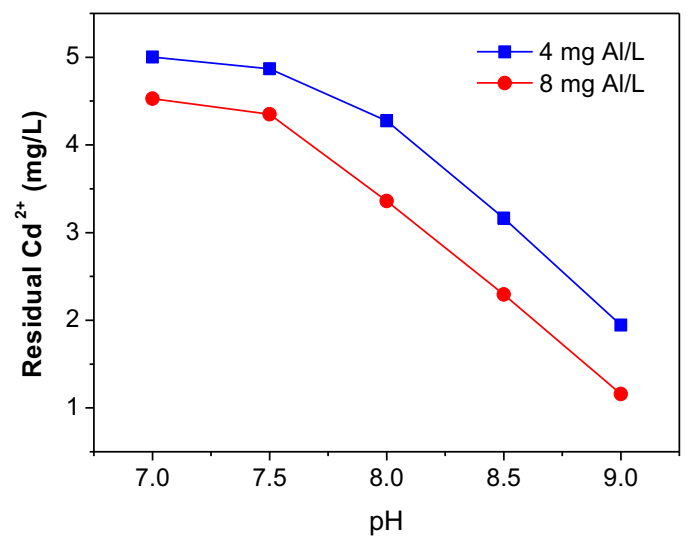

Fig. 4. Effect of $\mathrm{pH}$ on $\mathrm{Cd}^{2+}$ removal by PACC coagulation. Initial $\mathrm{Cd}^{2+}$ concentration was $5 \mathrm{mg} / \mathrm{L}$.

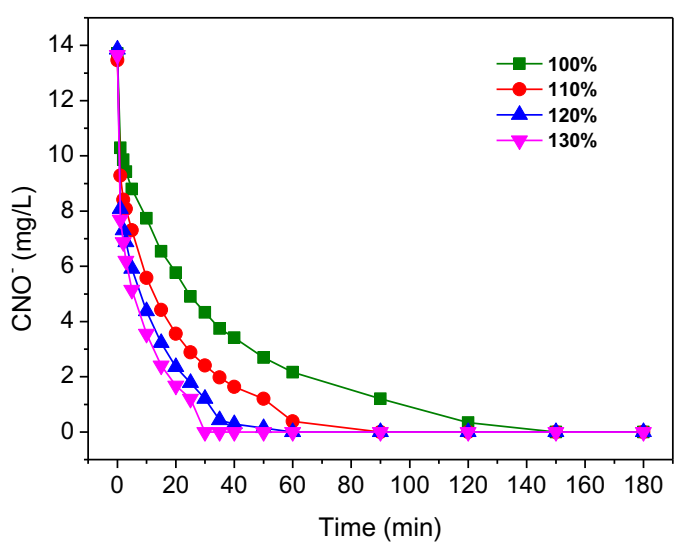

Fig. 5. $\mathrm{CNO}^{-}$concentration as a function of reaction time with various PACC dosages. The active chlorine $100 \%, 110 \%, 120 \%$ and $130 \%$ of the theoretical requirement for complete $\mathrm{CN}^{-}$oxidation were used. The initial concentration of $\mathrm{CN}^{-}$was $8.85 \mathrm{mg} / \mathrm{L}$. The reaction was terminated through adding $\mathrm{Na}_{2} \mathrm{SO}_{3}$ to ensure reaction time exactly.

$\mathrm{CNO}^{-}$to nitrate [20]. The active chlorine dosage $130 \%$ of the theoretical requirement and 30 min reaction time for $\mathrm{CNO}^{-}$decomposition are to be optimum.

The effect of PACC dose on $\mathrm{Cd}^{2+}$ removal by coagulation was studied at pH 8.5. As shown in Fig. 6, with PACC doses greater than $20 \mathrm{mg} \mathrm{Al} / \mathrm{L}, \mathrm{Cd}^{2+}$ removal maintained about $93 \%$ that is the maximal efficiency. As PACC doses increased from 0 to $20 \mathrm{mg} \mathrm{Al} / \mathrm{L}$, $\mathrm{Cd}^{2+}$ was linearly removed with a gradient of approximate 0.25 . These results suggests that for the treatment of $1 \mathrm{mg} / \mathrm{L} \mathrm{Cd}^{2+}$, the required minimal dosage to remove $\mathrm{Cd}^{2+}$ to the maximal efficiency by PACC was approximately $4 \mathrm{mg} \mathrm{Al} / \mathrm{L}$ at $\mathrm{pH}$ 8.5. In view of the treatment of $\left[\mathrm{Cd}(\mathrm{CN})_{4}\right]^{2-}$ by PACC under the optimal working conditions, the stoichiometric weight ratio of $\mathrm{Cl}_{2} / \mathrm{Al}$ in PACC was approximately 2, which is the optimal $\mathrm{Cl}_{2} / \mathrm{Al}$ weight ratio of PACC for $\left[\mathrm{Cd}(\mathrm{CN})_{4}\right]^{2-}$ removal. We prepared PACC2 with a $\mathrm{Cl}_{2} / \mathrm{Al}$ weight ratio of 2, which was used to further investigate the performance on $\left[\mathrm{Cd}(\mathrm{CN})_{4}\right]^{2-}$ removal.

\subsection{Process and performance of $\left[\mathrm{Cd}(\mathrm{CN})_{4}\right]^{2-}$ removal}

The performance of $\left[\mathrm{Cd}(\mathrm{CN})_{4}\right]^{2-}$ removal by PACC is closely related with dosage, $\mathrm{pH}$ and reaction time. According to above results, the process of $\left[\mathrm{Cd}(\mathrm{CN})_{4}\right]^{2-}$ removal by PACC is proposed in Fig. 7. Treatment process involved the two stages, whose $\mathrm{pH}$ values are 11 and 8.5, respectively. Reaction time included 13 min of the first stage and 30 min of the second stage. After the two stages

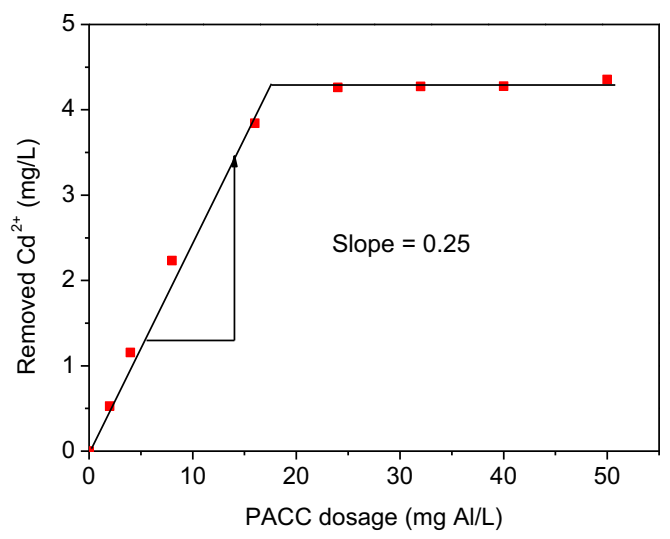

Fig. 6. Concentration plot of $\mathrm{Cd}^{2+}$ removal with PACC dosage at $\mathrm{pH} 8.5$. Initial $\mathrm{Cd}^{2+}$ concentration was $4.6 \mathrm{mg} / \mathrm{L}$. 


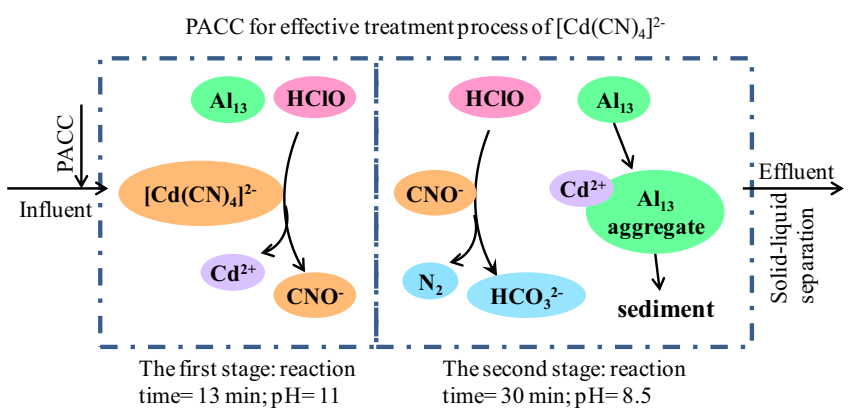

Fig. 7. Schematic diagram of the process of $\left[\mathrm{Cd}(\mathrm{CN})_{4}\right]^{2-}$ removal by PACC.

treatment and solid-liquid separation, effluent may meet the requirement of water treatment for $\mathrm{CN}^{-}$and $\mathrm{Cd}^{2+}$.

Special experiment was conducted to evaluate the performance of $\left[\mathrm{Cd}(\mathrm{CN})_{4}\right]^{2-}$ removal by PACC2 at the optimal working conditions. $\mathrm{NaClO}$ was used to make a comparison with PACC2. As shown in Fig. 8, $\mathrm{CNO}^{-}$was produced and accumulated continuously before the dosage of $12.8 \mathrm{mg} \mathrm{Cl}_{2} / \mathrm{L}$, which is the $\mathrm{SR}$ value of active chlorine to oxidize $\mathrm{CN}^{-}$to $\mathrm{CNO}^{-}$. The maximal concentration of formed $\mathrm{CNO}^{-}$was about $7.6 \mathrm{mg} / \mathrm{L}$. Whereafter, $\mathrm{CNO}^{-}$concentration decreased with the increase of active chlorine dosage, because the formed $\mathrm{CNO}^{-}$was further oxidized into nitrogen and bicarbonate. When active chlorine dosage was greater than $40 \mathrm{mg} \mathrm{Cl}_{2} / \mathrm{L}$, $\mathrm{CNO}^{-}$concentration was near zero. It indicated that $\mathrm{CN}^{-}$was completely oxidized by active chlorine. The trend of $\mathrm{CNO}^{-}$concentration with addition of PACC2 was very similar to that of $\mathrm{NaClO}$. However, there was a significant difference in removing $\mathrm{Cd}^{2+}$ between PACC and $\mathrm{NaClO}$. PACC showed a much higher ability to remove $\mathrm{Cd}^{2+}$ due to the function of $\mathrm{Al}_{13}$ coagulation. $\mathrm{Cd}^{2+}$ concentration decreased with increase of PACC2 dosage. After $\mathrm{CN}^{-}$ destruction by active chlorine in $\mathrm{PACC} 2, \mathrm{Cd}^{2+}$ was released from $\left[\mathrm{Cd}(\mathrm{CN})_{4}\right]^{2-}$ complex and subsequently removed by $\mathrm{Al}_{13}$ coagulation.
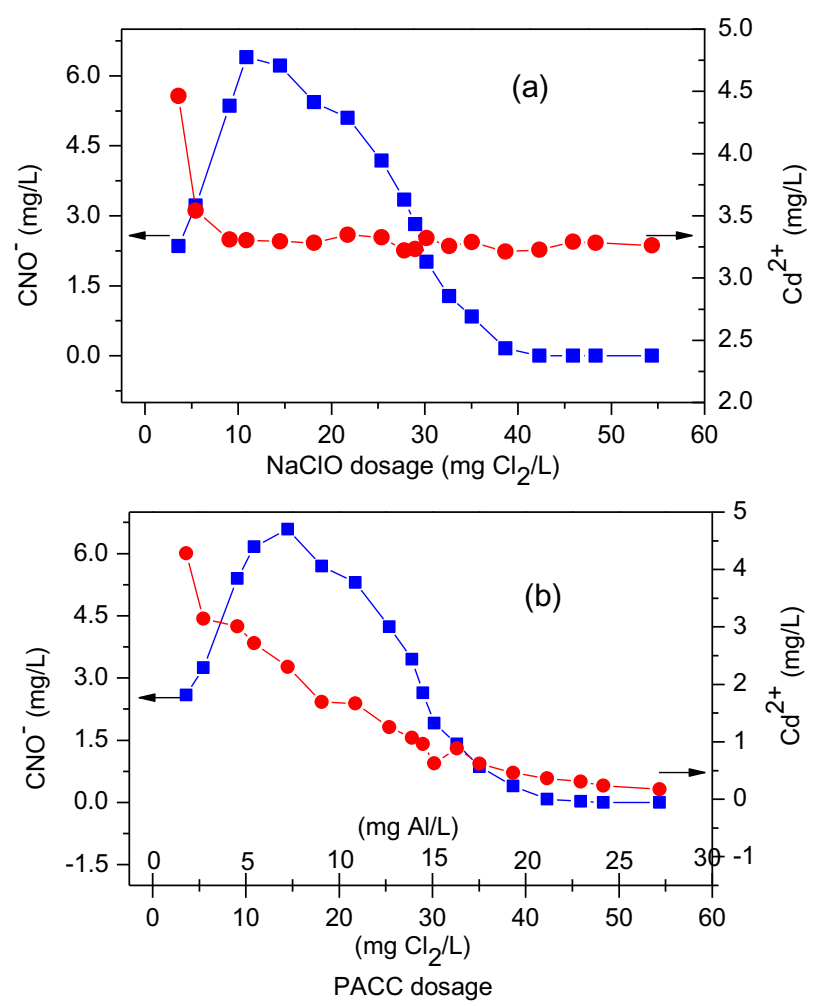

Fig. 8. $\mathrm{CN}^{-}$and $\mathrm{Cd}^{2+}$ removal by $\mathrm{NaClO}$ (a) and PACC2 (b). Initial $\left[\mathrm{Cd}(\mathrm{CN})_{4}\right]^{2-}$ concentration was $0.045 \mathrm{mmol} / \mathrm{L}$.

\section{Conclusions}

With high content of active chlorine and $\mathrm{Al}_{13}$ polymer, PACC is very effective for the treatment of $\mathrm{Cd}(\mathrm{CN})_{4}^{2-} . \mathrm{CN}^{-}$and $\mathrm{Cd}^{2+}$ can be simultaneously removed due to the combined function of oxidation and coagulation. The SR is $2.5 \mathrm{~mol} \mathrm{Cl}_{2} / \mathrm{mol} \mathrm{CN}^{-}$for the complete $\mathrm{CN}^{-}$oxidation by PACC. Two stages should be carried out for complete $\mathrm{CN}^{-}$oxidation and effective $\mathrm{Cd}^{2+}$ coagulation. The first stage involves the conversion of $\mathrm{CN}^{-}$to $\mathrm{CNO}^{-}$at $\mathrm{pH} 11$ and the second stage from $\mathrm{CNO}^{-}$to final product and the coagulation of the liberated $\mathrm{Cd}^{2+}$ at $\mathrm{pH}$ 8.5. The active chlorine dosage $130 \%$ of the theoretical requirement for $\mathrm{CN}^{-}$decomposition appears to be optimum. Under the optimal $\mathrm{pH}$ and dosage conditions, the reaction time for the first stage and the second stage should be $13 \mathrm{~min}$ and $30 \mathrm{~min}$, respectively. Under the optimal working conditions, the stoichiometric weight ratio of $\mathrm{Cl}_{2} / \mathrm{Al}$ in PACC is 2 for the treatment of $\left[\mathrm{Cd}(\mathrm{CN})_{4}\right]^{2-}$.

\section{Acknowledgment}

The authors are grateful for financial support from Natural Science Foundation of China (No. 51378490 and 51225805).

\section{References}

[1] C. Pohlandt, E.A. Jones, A.F. Lee, A critical-evaluation of methods applicable to the determination of cyanides, J. S. Afr. Inst. Min. Metall. 83 (1983) 11-19.

[2] S.R. Wild, T. Rudd, A. Neller, Fate and effects of cyanide during waste-water treatment processes, Sci. Total Environ. 156 (1994) 93-107.

[3] K.A. Baltpurvins, R.C. Burns, G.A. Lawrance, A.D. Stuart, Use of the solubility domain approach for the modeling of the hydroxide precipitation of heavy metals from wastewater, Environ. Sci. Technol. 30 (1996) 1493-1499.

[4] F. Fu, Q. Wang, Removal of heavy metal ions from wastewaters: a review, J. Environ. Manage. 92 (2011) 407-418.

[5] V.K. Sharma, C.R. Burnett, R.A. Yngard, D.E. Cabelli, Iron(VI) and iron(V) oxidation of copper(I) cyanide, Environ. Sci. Technol. 39 (2005) 3849-3854.

[6] R. Yngard, S. Damrongsiri, K. Osathaphan, V.K. Sharma, Ferrate(VI) oxidation of zinc-cyanide complex, Chemosphere 69 (2007) 729-735.

[7] R. Yngard, V.K. Sharma, J. Filip, R. Zboril, Ferrate(VI) oxidation of weak-acid dissociable cyanides, Environ. Sci. Technol. 42 (2008) 3005-3010.

[8] Y. Terashima, H. Ozaki, M. Sekine, Removal of dissolved heavy-metals by chemical coagulation, magnetic seeding and high-gradient magnetic filtration, Water Res. 20 (1986) 537-545.

[9] C.Z. Hu, H.J. Liu, J.H. Qu, Preparation and characterization of polyaluminum chloride containing high content of $\mathrm{Al}_{13}$ and active chlorine, Colloids Surf. A 260 (2005) 109-117.

[10] C. Hu, H. Liu, J. Qu, Optimum conditions for the formation of $\mathrm{Al}_{13}$ polymer and active chlorine in electrolysis process with $\mathrm{Ti} / \mathrm{RuO}_{2}-\mathrm{TiO}_{2}$ anodes, J. Environ. Sci. China 24 (2012) 297-302.

[11] C. Hu, H. Liu, G. Chen, W.A. Jefferson, J. Qu, As(III) oxidation by active chlorine and subsequent removal of $\mathrm{As}(\mathrm{V})$ by $\mathrm{Al}_{13}$ polymer coagulation using a novel dual function reagent, Environ. Sci. Technol. 46 (2012) 6776-6782.

[12] H. Zhao, C. Hu, H. Liu, X. Zhao, J. Qu, Role of aluminum speciation in the removal of disinfection byproduct precursors by a coagulation process, Environ. Sci. Technol. 42 (2008) 5752-5758.

[13] H. Zhao, J. Peng, S. Lin, Y. Zhang, Covalently bound organic silicate aluminum hybrid coagulants: preparation, characterization, and coagulation behavior Environ. Sci. Technol. 43 (2009) 2041-2046.

[14] W.K. Teo, C.S. Ng, Optimum conditions in cyanide destruction using hypochlorite, Chemsia Conference, Singapore, 1979.

[15] W.K. Teo, T.C. Tan, Hypochlorite oxidation of cyanate under mildly alkaline conditions, Water Res. 21 (1987) 677-682.

[16] G.E. Eden, B.L. Hampson, A.E. Wheatland, Destruction of cyanide in wastewater by chlorination, J. Soc. chem. 69 (1950) 244-249.

[17] C.Z. Hu, H.J. Liu, J.H. Qu, D.S. Wang, J. Ru, Coagulation behavior of aluminum salts in eutrophic water: significance of $\mathrm{Al}_{13}$ species and $\mathrm{pH}$ control, Environ. Sci. Technol. 40 (2006) 325-331.

[18] M. Yan, D. Wang, J. Qu, J. Ni, C.W.K. Chow, Enhanced coagulation for high alkalinity and micro-polluted water: the third way through coagulant optimization, Water Res. 42 (2008) 2278-2286.

[19] J.L. Lin, C. Huang, C.J.M. Chin, J.R. Pan, The origin of $\mathrm{Al}(\mathrm{OH})_{3}$-rich and $\mathrm{Al}_{13^{-}}$ aggregate flocs composition in PACl coagulation, Water Res. 43 (2009) 42854295.

[20] M.W. Lister, The reaction between cyanate and hypochlorite, Can. J. Chem. 34 (1956) 489-501. 